\title{
JUURNAL.RU
}

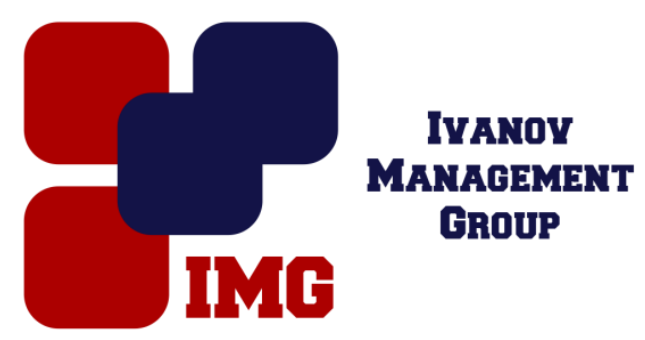

Журавлева И.А. Государственный Университет Управления Москва, Россия

doi: 10.18411/1j-30-04-2017-1-09

idsp 000001:1j-30-04-2017-1-09

\section{Социальная отчетность компании: предпосылки формирования единого стандарта}

\begin{abstract}
Аннотация
Нестабильность экономической ситуации и кризисы последних лет все чаще показывают бизнесу необходимость ориентироваться на стабильное развитие. Нефинансовые цели фирмы, такие как участие в жизни сообщества, формирование деловой репутации, забота об экологической ситуации, все чаще стали отодвигать на второй план получение краткосрочной прибыли. Однако оценить деятельность компании, направленную на поддержание устойчивого развития общества зачастую бывает проблематично, ввиду отсутствия единого стандарта отчетности.

Ключевые слова: социальная ответственность, социальная отчетность, разработка стандартов отчетности,

Недавние экономические кризисы все чаще указывают на необходимость фокусироваться на долгосрочном развитии компании, отодвигая на второй план показатели краткосрочной финансовой эффективности. В условиях социальноориентированной экономики становится обычным делом раскрытие информации о социальной ответственности компании, как один из способов получить доверие потребителей, партнеров и других заинтересованных сторон.

В ходе изучения данной темы было выявлено, что в России не существует единой трактовки понятия социальной ответственности бизнеса, как следствие, не разработано единой формы социальной отчетности бизнеса. На практике социальная отчетность компании означает открытое ведение бизнеса и
\end{abstract}


положительно влияет на имидж организации в глазах всех заинтересованных в ее деятельности сторон.

Данная проблема не теряет своей актуальности и для зарубежной практики, где вопросы социальной ответственности бизнеса поднимаются не первый год, однако разработать систему показателей и стандарты отчетности по вопросам социальной ответственности только предстоит.

Под корпоративной социальной ответственностью бизнеса прежде всего понимается добровольный вклад компании в развитие общества в социальной, экономической, экологической сферах, связанный напрямую с основной деятельностью компании и выходящий за рамки определенного законом минимума.

Такие аспекты социальной ответственности, как корпоративное управление, управление рисками, информация о воздействии на окружающую среду и взаимодействие с местным сообществом, благотворно оказывают сильное и постоянно увеличивающееся влияние на положение компании на рынке и ее способность генерировать прибыль в долгосрочном плане.

Таким образом, получение прибыли перестает быть главной целью для деятельности многих компаний как на зарубежном рынке, так и на Российском. Все чаще в мировом сообществе, на экономических форумах и конференциях поднимаются проблемы социальной ответственности бизнеса.

По определению «Глобальной инициативы по отчетности» (Global Reporting Initiative) (ГИО) термин «отчетность по устойчивому развитию» означает отчетность, которая охватывает одновременно экономические, экологические и социальные аспекты деятельности предприятия [4].

В ходе написания статьи были изучены многие работы отечественных и зарубежных авторов, в каждой из которых отмечалась необходимость разработки и внедрения стандартов социальной отчетности. В своей статье Воробьева О. А. отмечает, что бухгалтерское сообщество стран Запада признало важность нефинансовой отчетности еще в середине прошлого столетия. Так, в 1973 г. группа исследователей, отмечая важность социальной составляющей бухгалтерского учета, сделала вывод, что одна из главных целей корпоративной отчетности - сообщить информацию о тех действиях компании, которые оказывают непосредственное влияние на общество, в особенности, когда такое влияние может быть идентифицировано, описано и измерено. [1]

Данную проблему в своей статье поднимает Н. А. Николаев. Он отмечает необходимость разработки стандартов, и говорит о том, что поскольку 
инструментом социальной ответственности бизнеса является нефинансовая отчетность, важными в этом контексте стали вопросы разработки механизма соответствия корпоративной отчетности требованиям социальной экономики: определяются принципы, требования, подходы и положения, согласно которым должна составляться отчетность, внедряться соответствующие формы и их элементы. Поэтому все чаще стали озвучиваться мнения о том, что социальная ответственность должна найти свое отражение в системе бухгалтерского учета. [3]

В современном же мире внимание общества к деятельности компаний относительно экологии, благотворительным инициативам и вкладу в развитие сообщества только растет. Однако данный интерес в большинстве случаев остается не удовлетворенным в виду отсутствия в открытом у подавляющего большинства компаний какой-либо информации о их деятельности по социальным аспектам.

На данном этапе основным документом, дающим понятия социальной ответственности и социальной отчетности бизнеса, продолжает оставаться стандарт ISO 26000. Стандарт говорит, что основной составляющей оценки социальной ответственности и составления рейтингов компаний является учет текущей деятельности организации, а не только ее мероприятий в рамках программ КСО [1].

Автор данной статьи считает, что до момента, пока единого стандарта отчетности компаний по КСО не разработано, оценку деятельности компаний в данной сфере можно проводить в два этапа:

1. Социальный аудит и подготовка корпоративной отчетности в стандарте GRI. Целью данного стандарта является помощь организациям, публикующим отчеты, и сторонам, заинтересованным в их деятельности, выявить и осознать вклад организации в устойчивое развитие.

2. Верификация отчетности Компании по стандарту АA1000 (стандарт верификации АА1000 - стандарт оценки отчетности организации по показателям ее устойчивого развития, а также оценки лежащих в его основе процессов, систем и уровня компетентности).

Основными плюсами данной методики является, по мнению большинства экспертов, то, что организация при оценке своей деятельности с точки зрения социальной ответственности использует информацию, которую сама же и публикует в открытом доступе. Однако данные методики открытого ведения 
бизнеса не так широко распространены в условиях российской действительности и их внедрение сопряжено с определенными сложностями.

А. П. Жойдик отмечает их своей статье. Он говорит, что данные международные стандарты необходимо адаптировать для условий российской действительности; и должно пройти определенное время, для того, чтобы публикация нефинансовой отчетности стала нормой для российских организаций.[2].

Помимо этого в отечественной практике не хватает инициатив по внедрению социальной отчетности со стороны заинтересованных сторон. Под ними в данном случае принято понимать не только потребителей и партнеров, но также и государство, и работников самих организаций - иными словами всех, на кого деятельность компании оказывает либо может оказаться влияние.

Именно в силу отсутствия «спроса» на информацию о социальноориентированной деятельности, руководство компаний игнорирует необходимость предоставление открытого доступа к этой информации, не усматривая этом перспектив на долгосрочную выгоду.

Данная проблематика не раз обсуждалась на государственном уровне. Большинство инициатив здесь принадлежит Торгово-промышленной палате РФ. По инициативе участником, проводились круглые столы, в том числе по вопросам стандартизации и сертификации компаний в области корпоративной социальной ответственности. Первый итог работы - разработка и введение в действие стандарта, устанавливающего требования к КСО, и системы добровольной сертификации «СОЦСЕРТ». [6].

Авторы подавляющего большинства исследований, посвященных данной теме, сходятся во мнении, что главным мотивирующим фактором к внедрению практик социальной отчетности станет разработка единого формата отчетности. Он может быть разработан на основании стандартов финансовой и бухгалтерской отчетности, которые применяются во всех организациях, осуществляющих свою хозяйственную деятельности на территории Российской Федерации.

Показатели социальной ответственности компании можно найти в статье расходов компании на персонал, как на одну из заинтересованных сторон. В данном случае нас будет интересовать выплата исключительно «белой» заработной платы, своевременное отчисление средств во внебюджетные фонды, участие компании в развитии персонала. 
Также стоит принимать во внимание затраты компании на благотворительность, научно-исследовательские работы по усовершенствованию производства и снижению его неблаготворного влияния на окружающую среду. Публикация в открытом доступе такой информации повышает уровень доверия к бренду и положительно сказывается на долгосрочном развитии бизнеса.

На взгляд большинства ученых, он должен базироваться на принципах, описанных в стандарте ISO 26000 - открытость, обмен информацией, признание интересов заинтересованных сторон, вовлеченность компании в жизнь сообщества и заинтересованность в повышении качества жизни.

Внедрение стандартов ISO 26000 рассматривается как первый этап оценки состояния управления компанией по отношению к этому стандарту. Главная задача такой оценки - выявить области развития, повысить эффективность управления в сфере социальной ответственности организации. Эта задача приобрела особую актуальность в современных условиях экономической неопределенности.

\section{Заключение.}

Подводя итог, стоит еще раз отметить, что разработка единого стандарта социальной отчетности - на сегодняшний момент одна из важнейших проблем, стоящих на развития экономической и социальной сферы и вовлечения общества в устойчивое развитие данных сфер.

На основании изученного мною материала, можно сделать вывод о том, что реализация концепции корпоративной социальной ответственности в соответствии с ожиданиями и предпочтениями заинтересованных сторон будет не только способствовать развитию общества, но в долгосрочной перспективе, повысить экономическую эффективность компании. Поэтому всем хозяйствующим субъектам, а также общественно-экономическим организациям, не стоит пренебрегать актуальностью развития и внедрения системы оценки социальной ответственности бизнеса и разработкой единого стандарта отчетности. 
1. Воробьева О.А. Исторический экскурс: концепция корпоративной социальной ответственности как теоретическая основа нефинансовой отчетности // Российское предпринимательство. - 2015. - Том 16. — № 8. - с. 1111-1120.

2. Жойдик А.П. Методы оценки корпоративной социальной ответственности бизнеса // Российское предпринимательство. — 2013. — № 6 (228). — c. 94-98.

3. Николаев Н. А. Корпоративная социальная отчетность: проблемы повсеместного внедрения. // Федеральное государственное автономное образовательное учреждение высшего образования "СПбПУ Петра Великого". - 2013. - с. 501-505.

4. Официальный сайт Глобальной инициативы по отчетности - [Электронный ресурс]. 2017 - Режим доступа:- https://www.globalreporting.org/Pages/default.aspx (дата обращения: 15.03.2017).

5. Стандарт ГОСТ ИСО 26000 - [Электронный ресурс]. - Режим доступа : http://spbtpp.ru/wp-content/uploads/2015/11/law_national_standart.pdf

6. Торгово-промушленная палата РФ. Официальный сайт. - [Электронный ресурс]. Режим доступа: - http://tpprf.ru/ru/news/-i3813/ (дата обращения: 14.03.2017). 